\title{
Integrated Sediment Management in Rivers and Reservoirs
}

\author{
Jannes Kamphuis, Kristian Meerse \\ Dredging Consultancy Department, Royal IHC, Delft, The Netherlands \\ Email address: \\ j.kamphuis@ihcmti.com (J. Kamphuis),ka.meerse@royalihc.com (K. Meerse)
}

\section{To cite this article:}

Jannes Kamphuis, Kristian Meerse. Integrated Sediment Management in Rivers and Reservoirs. American Journal of Civil Engineering. Vol. 5, No. 6, 2017, pp. 315-319. doi: 10.11648/j.ajce.20170506.11

Received: August 8, 2017; Accepted: September 4, 2017; Published: September 26, 2017

\begin{abstract}
Dam instability and loss of storage capacity are just a few of many problems caused by reservoir sedimentation. With over 5000 large dams in India the impact of reservoir sedimentation is significant and therefore sediment management is of crucial importance. Where the majority of the dams have been clogged up during the past decades, the active removal of sediment from these reservoirs by dredging is necessary to regain its capacity. Sediment removal by dredging is a costly process. However, these costs can be reduced by implementing an innovative circular sediment management plan. By re-using the dredged sediments instead of disposing it as a waste product additional revenue could be generated. A consortium of Dutch companies are preparing a full-scale pilot project to implement the circular sediment management plan for reservoir dredging in India. This paper gives a brief overview of the projected pilot including a circular sediment management plan and a technical approach of the proposed dredging method.
\end{abstract}

Keywords: Reservoir, Dredging, Sedimentation, Circular Sediment Management, Rehabilitation, Pilot

\section{Introduction}

Most natural rivers have a more or less balanced sediment inflow and outflow. Dam construction dramatically affects this balance [1]. This creates an impounded reservoir which results in extremely low flow velocities and sediment trapping. Incoming sediment will be accumulated until the impounded reservoir has become 'filled up' and a new balance is achieved.

To date, 58,519 dams worldwide are registered by ICOLD (International Commission On Large Dams) [2]. The global net amount of reservoir storage space has been decreasing in recent years because reservoir sediment management was not standard practice in the past [3]. This trend is the result of a decrease in the rate at which reservoir storage has been added since about 1980 and the continued loss of storage space to reservoir sedimentation, Figure 1.

Figure 1 shows that total net reservoir storage space, after accounting for storage loss due to sedimentation, has decreased since about 2000, while global storage space per capita has decreased since about 1980. The current per

capita net reservoir storage space roughly equals what it was in 1965. The importance of implementing reservoir sediment management techniques to preserve reservoir storage space is evident.

Many sediment-related problems can occur both upstream and downstream of the dam [1]. Among others, there is a significant annual loss in reservoir storage and efficiency. Second, there is the abrasion of turbines and other hydro mechanical parts. This is caused by sediment hitting the parts of the turbine with large velocities. Third, there is the downstream impact. Rivers downstream of dams suffer from erosion and bank failure due to a reduced sediment load and occasional clear water releases. Fourth there is the ecological impact. Nutritious silt is trapped in the reservoir upstream what can result in less fertile soil downstream of the dam, influencing the local agriculture. There is an growing risk of instability of the hydro dams due to the pressure by weight because of the increasing amount of sediment. And finally siltation causes besides a decrease in operating losses (calculated on the basis of storage capacity) in many cases also a decrease in the drinking water stock in a time with a growing need of drinking water caused by urbanization. Beside these local challenges, there is a worldwide exhaustion of raw materials and an increasing need for water safety. Because of the continues siltation by nature of dams and reservoirs sediment management is essential in order to achieve long-term sustainable use. 


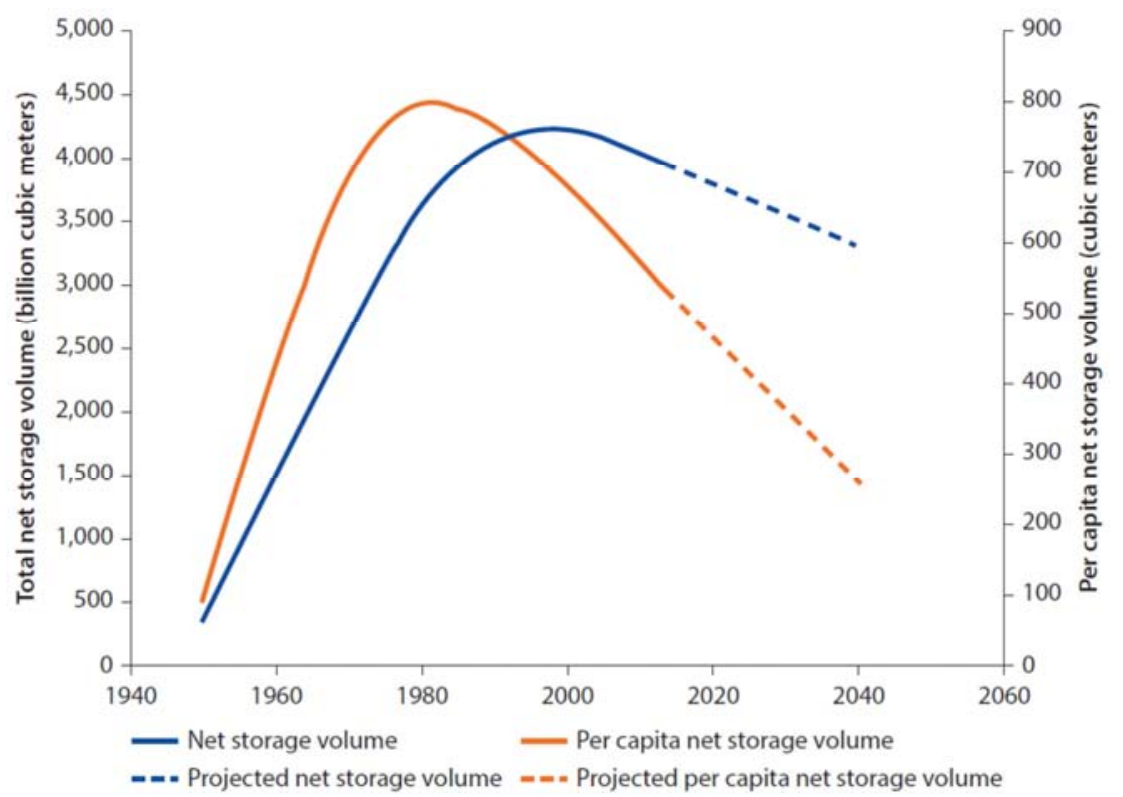

Figure 1. Net Global Reservoir Storage Volume, Accounting for Storage Loss from Reservoir Sedimentation [3].

\section{Circular Sediment Management}

\subsection{Reservoir Dredging}

One of the elements of sediment management is the removal of sediment by dredging [4] [5]. The removal of significant volumes of sediment from reservoirs characteristically entails dredging; the lifting of sediment from the bottom to the surface of a water body and deposition at another location. All sediment management methods related to dredging are costly [6]. Among others, this is because with the more traditional approach sediment is disposed as a waste product and most of the times deposit is not possible because of the inhospitable and poorly accessible locations of the reservoirs. However, once sediments have settled in a reservoir dredging is often the only management option available and therefore inevitable.

\subsection{Circular Sediment Management Plan}

To date, most of the dredged sediments from reservoirs are usually disposed as a waste product. This because in most cases the sediments are often seen as worthless and disposal possibilities are limited. The current state of affairs leads to the fact that there is a need for a major shift towards the concept of integrated sediment management considering collective benefits, sustainability and safety. Rapid development of cutting edge tools and technologies enables us to incorporate all available knowledge, concepts and approaches in an integrated manner.

Instead of disposing the sediments as a waste product they can be re-used for instance as a building material. There is a worldwide need for low-cost building materials and by reusing the sediment additional revenue could be created. Less raw materials have to be supplied for constructions and costs will drop significantly. Based on the potential opportunities and the local needs, a circular sediment management plan can be developed in which both the dredging and the re-use of the material is taken into account. Depending on the local situation sediment can be brought back in to the river or used for beneficial use.

Processing dredged sediment differs per situation. There is often a varying amount of sediment and there is a variety in sediment characteristics, known as the chemical and physical parameters. These two aspects are the main reason that there is no single optimal method available to process the silt from reservoirs. In addition, the re-use of silt in new applications varies strongly based on the ecological, economic and local requirements of the area. The ultimate goal is an optimal reuse of the sediment/silt from the reservoirs as well as downstream environmental supply. A sound circular sediment management plan should be developed with the supply of sediment on one hand and the beneficial reuse in all sorts of applications on the other.

\subsection{Long-Term Strategy}

Because sedimentation is an ongoing natural process a long-term strategy is required to minimize the future impact of sedimentation and to optimize operation and maintenance (O\&M) of the dam and reservoir. After the initial sediment removal the aim is to create an new balance with regard to the sediment in- and outflow. The long-term strategy will serve as a guideline to achieve long-term sustainable and efficient use of the system. By applying, for instance; water injection-/agitation dredging, flow regulation, regular flushing and regular sediment removal dredging the impact of sedimentation will be minimized and thus optimize O\&M costs.

Note: when regular removal dredging is applicable on the long-term, one piece of dredging equipment could be applied 
for multiple dams to further reduce the costs for dredging.

\section{Dredging Method}

\subsection{Dredging Types}

Dredging equipment can be classified into two broad categories: hydraulic and mechanical [7]. In hydraulic dredging the sediment is mixed with water and transported from the point of extraction to the point of placement as a sediment-water slurry. Mechanical dredges use buckets to dig and lift sediment to the surface with minimal water entrainment. One of the main parameters for selecting the best suitable dredging equipment are the soil characteristics [1]. These soil characteristics can vary a lot within a reservoir. The coarser sediment particles settle in the upstream of the reservoir where the velocity is considerably while finer particles are distributed over a longer distance up to the dam site. Difference in particle size and shape will greatly impact the characteristics and thus the behavior of soil. Therefore it is important to take and test soil samples close to the area that is to be dredged.

\subsection{Cable-Suspended Dredge Pump}

The proposed dredging method for the pilot is the 'cablesuspended dredge pump' as shown in Figure 2; a submergible dredge pump is lowered into the sediment via a cable (e.g. crane on pontoon or from the dam site) [1]. With this method great depths can be reached meanwhile generating very low turbidity, making it useful for instance at locations with turbidity restrictions. The efficiency of this method is highly depending on the specific grain distribution of the soil. When the sediments are coarse (e.g. gravel, sand) breaching can occur.

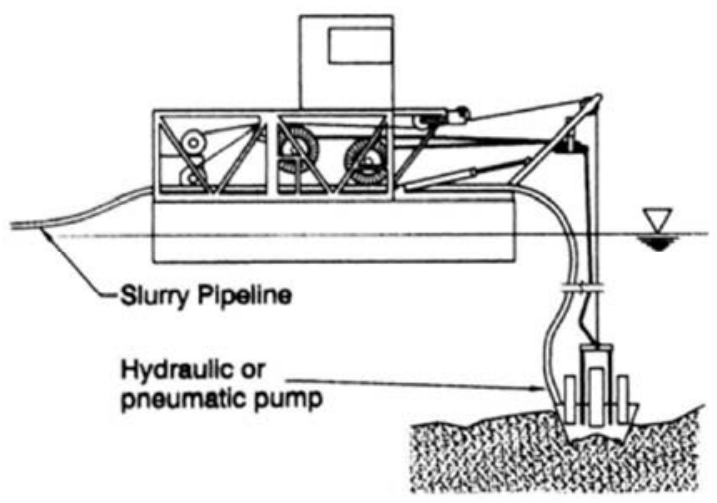

Figure 2. Cable-suspended dredge pump [1].

Breaching is the occurrence of continues and/or local instabilities on a sandy slope causing a density flow running downwards from the slope [8]. When the suction tube of a pump is lowered to a certain depth on a sandy layer, a hole with almost vertical slopes is being created around the suction tube. When time passes these vertical slopes move away radial from the suction tube, while the sand flows over a certain slope to the suction mouth, Figure 3.
The horizontal movements of these 'walls' are dependent on the soil characteristics and thus independent of the movement of the suction tube. The sand flow causes a density current that might further erode the slope of the suction mouth.

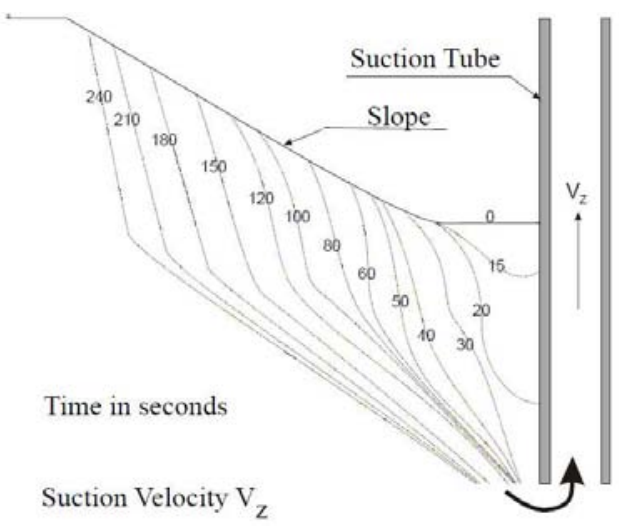

Figure 2. The Breaching Process [8].

The occurrence of breaching is depending on the stability of the sand particles. Since the particles are subjected to more forces than the gravity force (e.g. (ground-)water flow, dilatant/contractant flow) the following formula below is used to determine the stability [8].

$$
\frac{-v}{k}=\frac{\rho_{k}-\rho_{w}}{\rho_{w}}(\sin \gamma \cot \varphi-\cot \gamma)
$$

In which: $v=$ discharge velocity $[\mathrm{m} / \mathrm{s}], k=$ permeability $[\mathrm{m} / \mathrm{s}], \rho_{k}=$ density grain $\left[\mathrm{kg} / \mathrm{m}^{3}\right], \rho_{w}=$ density water $\left[\mathrm{kg} / \mathrm{m}^{3}\right], \gamma=$ slope angle $[\mathrm{deg}], \varphi=$ angle of internal friction [deg].

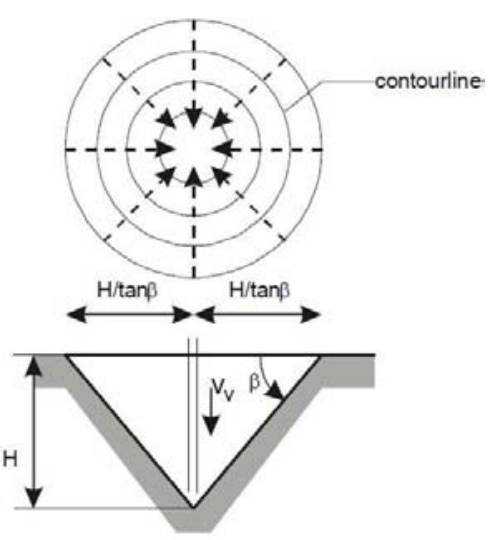

Figure 4. Vertical movement of the suction tube [8].

The estimated dredging production depends on the angle of the suction tube during movement. When the suction tube is being moved under an angle, the shape (and thus the volume) of the pit will differ from vertical movement of the suction tube. In this case the dredge pump is being lowered via a cable so the suction tube will mostly be moved vertically, Figure 4. The estimated production can be calculated as follows [8].

If the vertical speed of the suction tube is $\mathrm{v}_{\mathrm{v}}$ the slope will 
move in the horizontal direction with a speed:

$$
\begin{gathered}
v_{h}=\frac{v_{v}}{\tan \beta}=v_{w}\left(1-\frac{\tan \alpha}{\tan \beta}\right) \\
\rightarrow v_{v}=v_{w}(\tan \beta-\tan \alpha)
\end{gathered}
$$

Defining the depth of the pit as $H=f(t)$ then:

$$
\frac{d h}{d t}=v_{v}=v_{w}(\tan \beta-\tan \alpha)
$$

The volume of the pit is:

$$
V(t)=\frac{\pi}{3} \frac{H^{3}}{\tan ^{2} \beta}
$$

The production of the pit created by vertical movement of the suction tube can now be written as:

$$
\begin{aligned}
Q(H)=\frac{d V(t)}{d t}= & \frac{d V(t)}{d H} \frac{d H}{d t}=\frac{\pi}{\tan ^{2} \beta} H^{2} v_{v} \\
& =\frac{\pi}{\tan ^{2} \beta} H^{2}(\tan \beta-\tan \alpha) v_{w}
\end{aligned}
$$

The production calculation stated above applies to fairly coarse grain size diameters (upstream of the reservoir). When dredging close to the dam site smaller particle size are expected due to the lower velocities (e.g. silt, clay). Because of the (high) concentration of fines and colloids these sediment types are able to impart plastic properties at some water content, and the ability to resist shear stress at some other water content. This phenomenon is also known as 'cohesion' [1]. Because of the cohesive behavior the flow towards the suction head (e.g. production) is expected to be lower. Even with jet nozzles the production could be insufficient. In that case a Cutter Suction Dredger (CSD) would be a better solution taking into account the limited dredging depth.

\section{Pilot 'Circular Sediment Management' India}

\subsection{Objective}

A consortium of Dutch companies (Royal IHC, Deltares and NETICS) is planning to carry out a pilot project for reservoir dredging. The partnership envisaged a combination of specialistic knowledge to make clear that there are solutions to develop 'circular economy' solutions which are technical feasible and even can generate revenues. With this pilot we can demonstrate the feasibility (both economical, ecological and technical).

\subsection{Partners}

Deltares, Royal IHC and NETICS (the consortium) have the in-house knowledge and practical experience to design dedicated solutions based on the local context. The partnership under proposed consortium has added value given the fact that a joint execution with the combined competences of all the partners will enable us to offer a new knowledge- and technology based integrated approach, i.e. development of long-term sediment management strategy with the application of cutting edge knowledge and tools (Deltares), use of environmentally friendly dredging equipment and monitoring systems (Royal IHC) and naturefriendly, socially and economically effective sediment handling techniques and there applications based on a sound business plan for all stakeholders (NETICS). With this consortium we can offer a 'circular economy' solution. This by using a former waste product and treating that as a raw material to close the circle. Such partnership would be of strategic importance with the possibility of a long-term cooperation on a broad range of sediment-related concerns. Moreover, the consortium's pilot endeavor will be a valuable contribution to endow local industries and communities.

\subsection{Brief Description of Pilot}

After determining which reservoir can be used for the pilot (based on local circumstances and the potential for the reuse of sediment) soil samples have to be taken. This to determine the properties and expected behavior of the sediment during dredging of the reservoir. The initial plan is to use the TTpump with jet nozzles from IHC, Figure 6, to dredge the reservoir. The pump will be lowered via a cable operated with a crane on a pontoon or from the dam site.

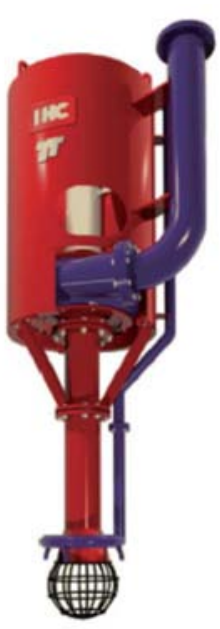

Figure 6. IHC TT-pump with jet nozzles [9].

During reservoir dredging, the dredged material will be pumped in to geotextile tubes at the chosen location. Geotextile tubes are a low-tech dewatering technique; the dredged material is pumped into tubes made of geotextile where the sludge is being dewatered and filtered in just a couple of weeks [10]. After dewatering the soil from the geotextile tubes can be prepared for re-use in both constructive and non-constructive applications (e.g.: roads, embankments, raising surface levels and sound barriers). The geotextile tubes are also directly applicable under civil constructions.

The re-use of silt from the reservoir can thus be coupled to 
the local demand. Hydraulic structures can be constructed to increase the water safety or infrastructure and housing to stimulate the local population and the economic growth in the area. Less raw materials have to be supplied for constructions and costs will drop significantly.

All the obtained data and knowledge during this pilot will be documented. A manual 'Circular sediment management plan' for reservoirs will be written. The recorded and documented footage will be used to create an informal film and paper about the sustainable reuse of sedimented silt in reservoirs.

\subsection{Project Funding}

The Dutch government has opened a subsidy scheme programme to encourage the use of Dutch innovate waterrelated solutions in foreign urban deltas and their supply systems. The subsidy of the Dutch government will contribute up to $60 \%$ of the projected pilot costs. The consortium is willing to finance the remaining $40 \%$ themselves.

\section{References}

[1] Morris, Gregory L. and Fan, Jiahua. "Reservoir Sedimentation Handbook", McGraw-Hill Book Co., New York, 1998, pp. 14, 23-28, 97, 507-524.
[2] International Commission On Large Dams (ICOLD). "World register of dams", 2017, http://www.icold-cigb.org/

[3] Annandale, George W., Gregory L. Morris, and Pravin Karki. "Extending the Life of Reservoirs: Sustainable Sediment Management for Dams and Run-of-River Hydropower.", 2016, World Bank, Washington DC.

[4] Palmieri, A., Shah, F., Annandale, G. W. and Dinar, A. "REServoir CONservation: The RESCON approach." Vol. I, 2003, The World Bank, Washington DC.

[5] Kawashima, S., Butler Johndrow, T., Annandale, G. W. and Shah, F. "Reservoir conservation: RESCON Model and User Manual." Vol. II, 2003, The World Bank, Washington DC.

[6] Mayau, X., de Bonviller, A., and Borbet, O. "Sedimentation in the Ruzizi 1 and 2 reservoirs: Means of response and forecasting.", 2017.

[7] Vlasblom, W. J. "Dredging equipment and technology - Chap 1: Introduction to dredging equipment", 2003.

[8] Vlasblom, W. J. "College WB3413 Dredging Process, The Breaching Process", 2003.

[9] Information on website Royal IHC, https://www.royalihc.com/en/products/dredging/otherdredging/tt-pumps, 2017

[10] Information on website NETICS, http://www.netics.nl/en/, 2017 